CASE REPORT

\title{
Asymptomatic 'big' hyperprolactinemia in two men with pituitary adenomas
}

\author{
Nicholas A Tritos, André T Guay and William B Malarkey ${ }^{1}$ \\ Section of Endocrinology, Lahey Hitchcock Medical Center, Burlington, Massachusetts, USA and ${ }^{1}$ Departments of Internal Medicine \\ and Medical Microbiology, The Ohio State University, Columbus, Ohio, USA
}

(Correspondence should be addressed to A T Guay, Section of Endocrinology, Center for Sexual Function, Lahey Hitchcock Northshore, One Essex Center Drive, Peabody, Massachusetts 01960, USA)

\begin{abstract}
'Big' and 'big-big' hyperprolactinemia, the presence of increased serum concentrations of high molecular weight (50-60 and $150 \mathrm{kDa}$ respectively) prolactin forms, has mostly been reported in women with idiopathic hyperprolactinemia and normal hypothalamic-pituitary ovarian axis function. It has been suggested that both 'big' and 'big-big' prolactin species are biologically less active than the $22 \mathrm{kDa}$ form predominating in normal individuals.

We report the cases of two men with pituitary adenomas who were secreting significant amounts of 'big' (50-60 kDa) prolactin documented by Sephadex G-100 column chromatography. Both patients reported normal sexual function despite high prolactin levels. Results of nocturnal rigidity and tumescence testing were normal, confirming that significant hyperprolactinemia was not interfering with either patient's sexual function. 'Big' hyperprolactinemia should thus be suspected even in male patients with prolactin-secreting pituitary adenomas who maintain adequate sexual function in the presence of high prolactin levels.
\end{abstract}

European Journal of Endocrinology 138 82-85

\section{Introduction}

Prolactin-secreting pituitary adenomas are the most common functioning pituitary tumors (1). Individuals with such lesions typically present with various combinations of amenorrhea, infertility, and galactorrhea in females and hypogonadism, impotence, diminished libido, and local compressive symptoms in males (2).

Over the past few years, several prolactin variants have been detected both in normal individuals and in a variety of disease states (3). Among them are the high molecular weight forms named 'big' (50-60 kDa) and 'big-big' (150 kDa) prolactin $(4,5)$. Macroprolactinemia has been defined as the presence of increased 'big' or 'big-big' serum prolactin levels (6). Both the 'big' and 'big-big' forms of hyperprolactinemia have been reported mostly in women with idiopathic hyperprolactinemia and normal menses and fertility $(5,7)$.

We have recently reported six men with erectile dysfunction and hyperprolactinemia secondary to high molecular weight prolactin forms ('big' and 'big-big' prolactin) (8). These patients had no radiologic evidence of pituitary or hypothalamic tumor. Both the normal nocturnal rigidity and tumescence studies as well as the resolution of their erectile dysfunction with counseling supported the diagnosis of psychogenic impotence. We present the cases of two male patients with pituitary tumors and high serum prolactin levels with a predominance of 'big' prolactin on gel filtration. Both men had normal libido and erectile function, suggesting that 'big' hyperprolactinemia was not interfering with their erectile function.

The study was presented in part at the American Association of Clinical Endocrinologists Fifth Annual Meeting and Clinical Congress, Seattle, WA, USA in May 1996.

\section{Case reports}

\section{Patient 1}

A 35-year-old man was referred to the endocrinology clinic because of the presence of an enlarged sella on sinus films. He reported normal erections and libido. He had no acromegalic features. He had no gynecomastia or galactorrhea. The testes were of normal size and consistency, and pubic hair was normal.

The basal serum prolactin level was $142080 \mathrm{mU} / \mathrm{l}$ (normal, up to $666 \mathrm{mU} / \mathrm{l}$ ), the serum total testosterone level was $4.1 \mathrm{nmol} / \mathrm{l}$ (normal, $13.9-41.6 \mathrm{nmol} / \mathrm{l}$ ), the 


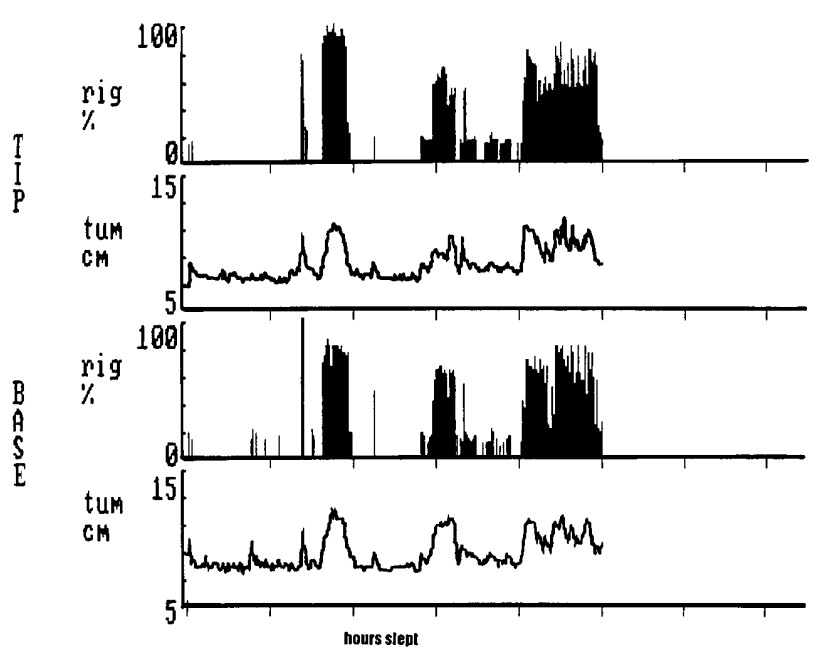

Figure 1 Nocturnal penile tracing in patient 1. Normal tumescence (tum) and rigidity (rig) values were noted both in the base and tip leads.

serum follicle-stimulating hormone level was $2 \mathrm{IU} / \mathrm{l}$ (normal, 1-7 IU/l), and the serum luteinizing hormone level was $5 \mathrm{IU} / \mathrm{l}$ (normal, 4-13 IU/l). The alpha subunit was $0.3 \mathrm{mg} / \mathrm{l}$ (normal, less than $1.0 \mathrm{mg} / \mathrm{l}$ ). The somatomedin C was $101 \mathrm{mg} / \mathrm{l}$ (normal, 90-318 mg/l). The serum thyrotropin level was $1.20 \mathrm{mIU} / \mathrm{l}$ (normal, 0.15$3.20 \mathrm{mIU} / \mathrm{l}$ ), and the free thyroxine level was $7.7 \mathrm{pmol} / \mathrm{l}$ (normal, 9.0-21.8 pmol/l). The morning serum cortisol level was less than $27 \mathrm{nmol} / \mathrm{l}$ and rose to $298 \mathrm{nmol} / \mathrm{l}$ (normal, more than $552 \mathrm{nmol} / \mathrm{l}$ ) on standard adrenocorticotropin stimulation testing. Serum sodium, potassium, and creatinine levels were normal. Magnetic resonance imaging (MRI) of the hypothalamus and pituitary showed a $3.2 \mathrm{~cm}$ sellar mass that was expanding the pituitary fossa. Goldmann perimetry showed a right superior temporal deficit and a full left field.

The patient was treated with bromocriptine, $2.5 \mathrm{mg}$ orally twice a day, and standard glucocorticoid replacement therapy, with improvement in his sense of wellbeing. Five months later, the serum prolactin level had decreased but was still elevated at $17760 \mathrm{mU} / \mathrm{l}$, the serum total testosterone level was near normal at $11.6 \mathrm{nmol} / \mathrm{l}$, and the serum free thyroxine level was $11.6 \mathrm{pmol} / \mathrm{l}$. As previously, he claimed that his libido and erectile function were normal. This claim was verified by nocturnal rigidity and tumescence testing, results of which were normal (Fig. 1). Chromatographic analysis of the serum prolactin level showed that it was $100 \%$ 'big' prolactin, eluting with a molecular weight of $60 \mathrm{kDa}$ (Table 1). A repeat MRI showed significant decrease in the size of the tumor $(2.0 \mathrm{~cm})$.

\section{Patient 2}

A 41-year-old man was first evaluated at our institution 18 months after transsphenoidal resection of a $2.8 \mathrm{~cm}$ pituitary tumor that stained positively for prolactin by immunohistochemistry. The preoperative serum prolactin level had been $46620 \mathrm{mU} / \mathrm{l}$. Because of radiologic evidence of residual pituitary tumor and persistently elevated prolactin levels, he had been treated with bromocriptine, up to $7.5 \mathrm{mg}$ a day, as well as radiotherapy to a total of $5000 \mathrm{cGy}$. Hypopituitarism had developed in the first year postoperatively, and the patient was given standard glucocorticoid, thyroid hormone, and intramuscular testosterone (300 mg every 3 weeks) replacement. Bromocriptine was discontinued because of nausea. The patient reported normal libido, erectile function, and overall sense of well-being. He had no gynecomastia or galactorrhea. The testes were $3 \times 2 \mathrm{~cm}$ each. Pubic hair was normal.

The serum prolactin level ranged between 9324 and $20868 \mathrm{mU} / \mathrm{l}$ when the patient was not taking bromocriptine. The patient reported normal erectile function and libido even after bromocriptine was discontinued, which was verified by normal results on nocturnal tumescence and rigidity testing. At that time, the serum prolactin level was $8880 \mathrm{mU} / \mathrm{l}$ (normal, up to $666 \mathrm{mU} / \mathrm{l}$ ), the serum total testosterone level was $17.2 \mathrm{nmol} / \mathrm{l}$ (normal, more than $13.9 \mathrm{nmol} / \mathrm{l}$ ), the serum free testosterone level was $485.4 \mathrm{pmol} / \mathrm{l}$ (normal, more than $173.3 \mathrm{pmol} / \mathrm{l}$ ), both 1 week after a testosterone injection, and the free thyroxine level was $16.7 \mathrm{pmol} / \mathrm{l}$ (normal, 10.3-24.5 pmol/l). Chromatographic analysis of the patient's serum prolactin showed a preponderance of 'big' prolactin (see Table 1). A repeat MRI showed no significant change in the size of the residual tumor.

\section{Materials and methods}

\section{Prolactin assay}

The serum concentration of prolactin was measured by double antibody RIA, employing ${ }^{125}$ I-human prolactin

Table 1 Chromatographic distribution of serum prolactin (PRL) in two men with prolactin-secreting pituitary tumors and normal erectile function.

\begin{tabular}{lcccc}
\hline Patient & $\begin{array}{c}\text { Serum PRL } \\
(\mathrm{mU} / \mathrm{l})\end{array}$ & 'Big-big' (150 kDa) PRL (\% total) & 'Big' (55-60 kDa) PRL (\% total) & Monomeric (22 kDa) PRL (\% total) \\
\hline 1 & 17760 & 0 & 100 & 0 \\
2 & 8880 & 0 & 53 & 47
\end{tabular}

Normal concentrations: PRL: 88.8-666 mU/l; 'big-big' PRL: <15\%; 'big' PRL: <15\%; monomeric PRL: >70\%. 
(Dupont, Boston, MA, USA), the NIDDK-hPRL-RP-1 human prolactin reference standard, and the NIDDKhPRL-3 rabbit prolactin antiserum. A second antibody immunoprecipitation antibody step was employed. All samples were assayed in duplicate. The intra-assay and interassay coefficients of variation were $6 \%$ and $8 \%$ respectively.

\section{Gel filtration chromatography}

Gel filtration chromatography was performed using Sephadex (G-100) 90×1.5 cm columns equilibrated and run in a cold room $\left(4^{\circ} \mathrm{C}\right)$. Equilibration and running solution contained $25 \mathrm{~mm}$ Tris- $\mathrm{HCl}$ and $0.1 \%$ sodium azide, $\mathrm{pH}$ 8.0. Molecular weight markers used for column calibration included dextran blue, ribonuclease, chymotrypsinogen, ovalbumin, ${ }^{125}$ I-prolactin, and aldolase (Sigma, St Louis, MO, USA); $1.5 \mathrm{ml}$ fractions were collected at a flow rate of $9 \mathrm{ml} / \mathrm{h}$. The optical density of all column fractions was measured on a Beckman Du-8 spectrophotometer (Beckman Instruments, Palo Alto, CA, USA), and the prolactin concentration of all fractions was measured by RIA as previously described. 'Big' and 'big-big' prolactin each normally accounts for up to $15 \%$ of total prolactin immunoreactivity $(6,8)$.

\section{Nocturnal penile rigidity and tumescence study}

Each patient underwent a formal nocturnal penile rigidity and tumescence study on two consecutive nights using a RigiScan portable home monitor (Dacomed Corp., Minneapolis, MN, USA). Data were analyzed on an IBM 480 microcomputer employing RigiScan Windows software (Dacomed Corp.)

\section{Discussion}

Hyperprolactinemia is associated with a variety of sexspecific clinical manifestations, of which erectile dysfunction is consistently present in men. Thus, in a series (9) of 22 male patients with prolactin-secreting pituitary tumors, 91\% had erectile dysfunction and decreased libido. In another study (10), as many as $100 \%$ of patients with hyperprolactinemia were impotent.

The mechanism by which high serum prolactin levels cause impotence is not universally agreed upon. Interestingly, the serum testosterone level is often normal in patients with hyperprolactinemia who have impotence on presentation. Thus, in one study (1), 7 of 17 patients with impotence and idiopathic hyperprolactinemia had normal serum testosterone levels. Furthermore, bromocriptine therapy decreased serum prolactin levels and restored potency before the serum testosterone level increased into the normal range in five of six patients (11). In a different study (12), two patients with hyperprolactinemia and resistance to bromocriptine experienced no improvement in erectile function despite testosterone replacement, suggesting that hyperprolactinemia in itself may lead to erectile dysfunction irrespective of testosterone levels.

Over the past few years, there has been growing awareness of the heterogeneity of serum prolactin, with the recognition of 'big' and 'big-big' prolactin $(4,5)$. In contrast, the prevalence of 'big' or 'big-big' macroprolactinemia in American populations is not known. However, a survey in Japan (4) found that $0.4 \%$ of adult women had asymptomatic 'big' macroprolactinemia. The prevalence of hyperprolactinemia in this population was $1.2 \%$. In contrast, in the same study, only $0.02 \%$ of adult men had macroprolactinemia. In another study (13), only 1 of 605 healthy individuals $(0.15 \%)$ and none of 11 patients with prolactinomas were found to have hyperprolactinemia secondary to 'big-big' prolactin. In a different survey from Japan (14), the prevalence of macroprolactinemia secondary to 'big-big' prolactin was $2.9 \%$ among pregnant women.

Female patients with macroprolactinemia are mostly asymptomatic $(4,7,15)$. In one study $(7)$, only one of five female patients with 'big' macroprolactinemia had radiologic evidence of a pituitary microadenoma. Three additional patients with prolactinomas and increased contribution from high molecular weight prolactin forms have been reported (16). Only one female patient in that report showed a preponderance of 'big-big' prolactin on gel filtration studies.

Reports of men with macroprolactinemia are rare. Wortsman et al. (17) reported two adult men with 'bigbig' macroprolactinemia and no radiologic evidence of a pituitary tumor, one of whom had normal erectile function. Garnier et al. (18) described a series of patients with pituitary tumors and measurable 'big' prolactin levels. Only one man in that series had an excess of 'big' prolactin. However, no comment was made about the patient's erectile function. We (8) recently reported on six adult men with erectile dysfunction and idiopathic 'big' or 'big-big' macroprolactinemia whose symptoms resolved with appropriate counseling. To our knowledge, the two patients presented here are the only reported male subjects with 'big' macroprolactinemia secondary to pituitary adenomas who were documented to have intact erectile function.

Given the fact that the overwhelming majority of men with prolactin-secreting pituitary adenomas have erectile dysfunction, we suggest that documentation of normal erectile function in our patients, despite high 'big' prolactin levels, is evidence for decreased bioactivity of 'big' prolactin. It has been suggested that both 'big' prolactin has decreased receptor affinity (18), whereas 'big-big' prolactin has decreased bioavailability (19). However, it should also be noted that both patients had biochemically documented secondary hypogonadism. Although we cannot exclude the possibility that 'big' prolactin could be playing an etiologic role, we believe that hypogonadism more probably reflected pressure 
effects on the gonadotrophs by these large tumors or, in our second patient, the potentially detrimental effects of surgery and radiotherapy on pituitary gonadotrophs.

In summary, we have presented the first two male subjects with pituitary tumors and 'big' macroprolactinemia who were documented to have intact sexual function despite high prolactin levels. Thus 'big' macroprolactinemia should be suspected even in individuals with prolactinomas in the absence of clinical manifestations.

\section{Acknowledgements}

The authors wish to thank Dr Paramjeet Sabharwal and Dr Supriya Varma for their assistance in performing the gel filtration studies on serum samples. This study was funded in part by NIH General Clinical Research Center grant MOI-RR0034.

\section{References}

1 Laws ER Jr, Ebersold MJ, Piepgras DG, Abboud CF, Randall RV \& Scheithauer BW. Role of surgery in the management of prolactinoma. In Prolactin. Basic and Clinical Correlates, pp 849853. Eds RM Macleod, MO Thorner \& U Scapagnini. Padova: Liviana Press, 1985.

2 Besser GM, Wass JA, Grossman A, Ross R, Doniach I, Jones AE et al. Clinical and therapeutic aspects of hyperprolactinemia. In Prolactin. Basic and Clinical Correlates, pp 833-847. Eds RM MacLeod, MO Thorner \& U Scapagnini. Padova: Liviana Press, 1985.

3 Sinha YN. Structural variants of prolactin: occurrence and physiological significance. Endocrine Reviews 199516 354-369.

4 Miyai K, Ichihara K, Kondo K \& Mori S. Asymptomatic hyperprolactinemia and prolactinoma in the general population - mass screening by paired assays of serum prolactin. Clinical Endocrinology 198625 549-554.

5 Whittaker PG, Wilcox T \& Lind T. Maintained fertility in a patient with hyperprolactinemia due to big, big prolactin. Journal of Clinical Endocrinology and Metabolism 198153 863-866.

6 Jackson RD, Wortsman J \& Malarkey WB. Macroprolactinemia presenting like a pituitary tumor. American Journal of Medicine 198578 346-350.
7 Corenblum B. Asymptomatic hyperprolactinemia resulting from macroprolactinemia. Fertility and Sterility 199053 165-167.

8 Guay AT, Sabharwal P, Varma S \& Malarkey WB. Delayed diagnosis of psychological erectile dysfunction because of the presence of macroprolactinemia. Journal of Clinical Endocrinology and Metabolism 199681 2512-2514.

9 Carter JN, Tyson JE, Tolis G, Van Vliet S, Faiman C \& Friesen HG. Prolactin-secreting tumors and hypogonadism in 22 men. New England Journal of Medicine 1978299 847-852.

10 Spark RF, Wills CA, O'Reilly G, Ransil BJ \& Bergland R. Hyperprolactinemia in males with and without pituitary macroadenomas. Lancet 19822 129-132.

11 Buvat J, Lemaire A, Buvat-Herbaut M, Fourlinnie JC, Racadot A \& Fossati P. Hyperprolactinemia and sexual function in men. Hormone Research 198522 196-203.

12 Nagulesparen M, Ang V \& Jenkins JS. Bromocriptine treatment of males with pituitary tumours, hyperprolactinaemia, and hypogonadism. Clinical Endocrinology 1978 9 73-79.

13 Bjoro T, Morkrid L, Wergeland R, Turter A, Kvistborg A, Sand T et al. Frequency of hyperprolactinemia due to large molecular weight prolactin (150-170 kD PRL). Scandinavian Journal of Clinical and Laboratory Investigation 199555 139-147.

14 Hattori N. The frequency of macroprolactinemia in pregnant women and the heterogeneity of its etiologies. Journal of Clinical Endocrinology and Metabolism 199681 586-590.

15 Malarkey WB, Jackson R \& Wortsman J. Long-term assessment of patients with macroprolactinemia. Fertility and Sterility 198850 413-418.

16 Cavaco B, Leite V, Santos MA, Arranhado E \& Sobrinho LG. Some forms of big-big prolactin behave as a complex of monomeric prolactin with an immunoglobulin $\mathrm{G}$ in patients with macroprolactinemia or prolactinoma. Journal of Clinical Endocrinology and Metabolism 199580 2342-2346.

17 Wortsman J, Carlson HE \& Malarkey WB. Macroprolactinemia as the cause of elevated serum prolactin in men. American Journal of Medicine 198986 704-706.

18 Garnier PE, Aubert ML, Kaplan SL \& Grumbach MM. Heterogeneity of pituitary and plasma prolactin in man: decreased affinity of big prolactin in a radioreceptor assay and evidence for its secretion. Journal of Clinical Endocrinology and Metabolism 1978 47 1273-1281.

19 Jackson RD, Wortsman J \& Malarkey WB. Characterization of a large molecular weight prolactin in women with idiopathic hyperprolactinemia and normal menses. Journal of Clinical Endocrinology and Metabolism 198561 258-264.

Received 22 May 1997

Accepted 22 September 1997 